Int. J. Environ. Res. Public Health 2007, 4(4), 289-295

International Journal of

Environmental Research and Public Health

ISSN 1661-7827

www.ijerph.org

(C) 2007 by MDPI

\title{
Psychometric Evaluation of a Coping Strategies Inventory Short-Form $(C S I-S F)$ in the Jackson Heart Study Cohort
}

\author{
Clifton C. Addison ${ }^{1 *}$, Brenda W. Campbell-Jenkins ${ }^{1}$, Daniel F. Sarpong1, Jeffery Kibler ${ }^{2}$, Madhu Singh ${ }^{3}$, Patricia \\ Dubbert $^{4}$, Gregory Wilson ${ }^{1}$, Thomas Payne ${ }^{5}$ and Herman Taylor ${ }^{6}$
}

${ }^{1}$ Jackson Heart Study Coordinating Center, Jackson, MS; ${ }^{2}$ Nova Southeastern University, Pensacola, FL; ${ }^{3}$ Tougaloo College, Tougaloo, MS; ${ }^{4}$ Veterans Administration Medical Center, Jackson, MS; ${ }^{5}$ University of Mississippi Medical Center, Jackson,

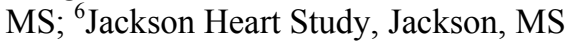

*Correspondence to Dr. Clifton C. Addison: clifton.addison@jsums.edu

Received: 17 October 2007 / Accepted: 30 November 2007 / Published: 31 December 2007

\begin{abstract}
This study sought to establish the psychometric properties of a Coping Strategies Inventory Short Form (CSI$S F$ ) by examining coping skills in the Jackson Heart Study cohort. We used exploratory and confirmatory factor analysis, Pearson's correlation, and Cronbach Alpha to examine reliability and validity in the CSI-SF that solicited responses from 5302 African American men and women between the ages of 35 and 84. One item was dropped from the 16-item CSI-SF, making it a 15-item survey. No significant effects were found for age and gender, strengthening the generalizability of the CSI-SF. The internal consistency reliability analysis revealed reliability between alpha $=0.58-0.72$ for all of the scales, and all of the fit indices used to examine the CSI-SF provided support for its use as an adequate measure of coping. This study provides empirical support for utilizing this instrument in future efforts to understand the role of coping in moderating health outcomes.
\end{abstract}

Keywords: Measurement; psychometric analysis; coping; African Americans

\section{Introduction}

Cardiovascular disease (CVD) remains the number one cause of death in the United States. A number of risk factors for coronary heart disease (CHD) and stroke have been identified, and population-based studies have begun to examine CVD risk prospectively in African Americans. Recent literature has established that death rates for CVD in the U.S. are disproportionately higher for African Americans [1-4]. The assessment of psychosocial factors, such as coping, is critical for a comprehensive understanding of cardiovascular risk and health [5]. Coping is believed to moderate the relationship between environmental stressors and physiological responses that ultimately influence health outcomes [6], signifying that defensive coping can modify the impact of hostile encounters on physiological functioning [7;8], and problem-focused coping can enable individuals with higher coping skills to have fewer depressive symptoms [9-13].

Racial differences in chronic disease survival have been attributed in the past to lack of education, lower socioeconomic status, inadequate medical insurance, and limited access to healthcare. The difference in chronic disease survival between African American women and white women has been linked to differences in coping strategies employed by these two groups. [14-16]. It is believed that coping strategies by individuals with chronic diseases could help to explain the differences in their disease survival rates, as well as their ability to adjust to chronic diseases [17]. Even though some authors have described coping mechanisms as innate or acquired methods that individuals use to respond to internal or external stimuli, exploration of coping strategies used by African Americans has not been very well defined in the literature [18]. Coping strategies are essential for 
adaptation and survival, but the experiences of African Americans with traditional health care services do not provide them with adequate adjustment to chronic diseases. It has been reported that African Americans, however, generally assimilate information through a cultural context, using positive reappraisal, social support, and problem-solving that may have an impact on their survival rates when confronted with chronic diseases [19].

The original Coping Strategies Inventory (CSI) was developed to categorize coping responses based on coping target and directionality of response [20]. With this system, individuals are classified using a $2 \times 2$ matrix that quantifies the degree to which each strategy is generally employed. Coping efforts are first categorized as to whether they represent an engagement strategy, involving approach-related actions that result in confronting stressors, often viewed as a crucial factor in limiting the long-term psychological and physiological sequelae of environmental stressors, or disengagement strategy (avoidance) seeking to limit exposure to noxious stimuli, often producing desirable short-term effects, but leading to longer-term problems, including depressive symptoms [6;21]. Within these categories, the target of the coping effort is either Problem-focused or Emotion-focused [2123]. Emotion-focused coping emphasizes the regulation of one's affective response, whereas Problem-focused coping emphasizes management of the stress-producing situation.

Despite the myriad of stressors to which most African Americans are exposed, relatively little is known about patterns of coping in this population. When faced with stressful life circumstances, the general tendency is to react cognitively and/or behaviorally to reduce the effects of those experiences [7, 18, 24-26]. The science of psychometrics includes a set of standards and procedures by which to judge the characteristics and quality of a survey. A major goal of establishing psychometric properties is an evaluation of the consistency of psychometric results [27]. The purpose of this study was to expand previous studies of coping through an examination of the psychometric properties and the factor structure of the Coping Strategies Inventory Short Form (CSI-SF) that was administered to the Jackson Heart Study African American cohort.

\section{Methods}

The participants of this study comprised the Jackson Heart Study (JHS) cohort with a representative, population-based sample that includes 5302 African American men and women between the ages of 35 and 84. Power analyses confirmed that all scientific questions could be addressed with this sample. The sample is made up of four components of participants who are residents of Hinds, Madison and Rankin counties surrounding Jackson, Mississippi; Atherosclerosis Risk in Communities (ARIC) participants; random selection participants; volunteers; and family participants-- first degree relatives of index participants. There were 931 participants in the random group, 1570 in the volunteer group, 1185 in the ARIC group and 1626 in the family group, making a total of 5302 in the sample. Further details of the Jackson Heart Study sample are chronicled elsewhere [28].

The CSI was selected because it was believed to adequately address the question of coping, it addressed factors that were crucial to the study model, it was pertinent to theory, and it classified coping in a way that was believed to have established empirical support extending across age groups [29]. The CSI was originally constructed as a 78-item questionnaire [20]. A four point Likert scale was used to record the participants' responses. Respondents were asked to rate the general frequency with which they utilize each listed coping strategy on the survey and to indicate their choices in the following manner: 1 = "Never", 2 = "Seldom", 3 = "Sometimes", 4 = "Often" and 5 = "Almost Always".

The original CSI was shortened to a 16-item version for use in the JHS, after a validation study was conducted in Jackson, Mississippi, using research samples including headache sufferers, patients with coronary heart disease, and caregivers of Alzheimer's patients [30]. The CSI-SF was structured to reflect the original scale, with four 4item subscales: (a) Problem-Focused Engagement, (b) Problem-Focused Disengagement, (c) Emotion-Focused Engagement, and (d) Emotion-Focused Disengagement [20]. Individuals receive scores for each first tier subscale (Engagement and Disengagement: range $=8-40$ ), as well as for each of the four second tier subscales (Problem-Focused Engagement, Problem-Focused Disengagement, Emotion-Focused Engagement, and Emotion-Focused Disengagement: range $=4-20$ ). Each of the four $2^{\text {nd }}$ tier subscales created contained four items each [31].

Use of the 16 item CSI-SF in the JHS was believed to meet minimum psychometric requirements for measuring coping in this African-American population. It was believed that the methods used to construct and score the scales, as well as the summary measures, were appropriate for the group under investigation [29]. Participants of the JHS were instructed by Jackson Heart Study Home Induction Interviewers to complete the CSI$S F$ at home, prior to their clinic exams, and deliver it at their clinic exam visit. At that visit, an interviewer reviewed the form for completeness and for assurance that the participant had a clear understanding of instructions and content Interviewers would read instructions and questions aloud if the participant had a reading disability or other impediment that pre-empted their ability to fully comprehend the instructions and procedures [30].

\section{Statistical Analysis}

Our analyses evaluated whether the original CSI subscale configuration and its psychometric features had been maintained in this new 16-item CSI-SF instrument. Data collected were first examined by applying descriptive statistics procedures, using frequencies, mean 
and standard deviations. A comparison of JHS participants who completed the CSI-SF and those who did not complete the CSI-SF was made to examine differences relevant to the study, and to ensure that nonresponse bias was not a problem [32].

The decision as to which approach to use depends largely on the current understanding of the factors under investigation. Two of the most widely used methods of factor analysis were considered for this study. Floyd and Widaman [31] suggested that exploratory factor analysis (EFA) is most appropriate in the initial stages of model development. An exploratory factor analysis can first be applied if it is unclear that a theory is sufficiently developed to justify a confirmatory analysis [33]. Confirmatory factor analysis (CFA) provides a more powerful tool in the second stage of research when a model has already been established. In the case of the CSI-SF, a highly promoted model was already available in the literature, and exploratory factor analysis (EFA) was not necessary to examine and verify the factor structure [31]. We decided to examine the validity of the revised 16-item CSI-SF through a preliminary exploratory factor analysis, and then tested these factors using CFA. The objective of conducting the EFA was to detect any low, inadequate factor loadings and delete such low loadings of response items from the model that would ultimately represent the coping characteristics of the JHS cohort. To be considered meaningful, the standardized path coefficients of the items should be above .30 [34;35].

CFA was subsequently applied to this factor solution since this is the appropriate measure when a model has already been established [31]. The output of CFA allows the researcher to evaluate the factor model overall, and, at the same time, evaluate the level of individual variablefactor relationships [36], in order to develop an adequate instrument for measurement [37].

Since the CSI-SF was developed by first identifying coping dimensions and then selecting items to measure those dimensions from the original CSI, an a priori structure was established, and the CFA conducted in this study sought to determine how well the previously created structure conformed to the data. Next, a structural equation modeling (SEM) procedure was conducted to examine the relationship among the many variables simultaneously. The PROC CALIS procedure in SAS was used to conduct the CFA. Internal consistency reliability coefficients were calculated based on Cronbach's alpha coefficient $[35,38]$. With this procedure, the chi-square was first conducted to test the fit between the sample covariance matrix and the matrix implied by the models. This chi-square statistic was utilized to test the difference between the predicted and the observed relationships (correlations/co-variances). Calculations were computed for Root Mean Square Error of Approximation (RMSEA), Goodness of Fit Index (GFI), Root Mean Square Residual (RMSR), Adjusted Goodness of Fit Index (AGFI), Parsimonious GFI (PGFI) and Parsimonious NFI (PNFI) $(35,39-41)$. Validity analysis focused on construct validity. The Pearson correlation coefficient was computed for this purpose to assess the associations among the scales.

\section{Results}

The CSI-SF was given to all 5302 enrolled participants in the JHS. Of these participants, $81.4 \%$ provided a completed measure, while $18.6 \%$ did not. To investigate selection bias issues and to evaluate any potential variation between participants who completed the CSI-SF and those who did not complete the instrument, Chi-square analyses were computed on some demographic data that could relate to the response to the instrument. Table 1 displays analyses that were computed on gender, educational level, and income level of the participants to examine non-response bias between those who responded to the CSI-SF and those who did not.

Table 1: Demographic Characteristics of Respondents (Completing the CSI-SF) and Non-Respondents (Not Completing CSI-SF)

\begin{tabular}{|c|c|c|c|c|c|}
\hline \multirow[t]{2}{*}{ Category } & \multicolumn{2}{|c|}{ Respondents } & \multicolumn{2}{|c|}{$\begin{array}{c}\text { Non } \\
\text { Respondents }\end{array}$} & \multirow{2}{*}{$\begin{array}{r}p- \\
\text { value }\end{array}$} \\
\hline & $n$ & $\%$ & $n$ & $\%$ & \\
\hline \multicolumn{6}{|l|}{ Gender } \\
\hline Female & 2807 & 65.1 & 586 & 59.4 & \multirow{2}{*}{.0008} \\
\hline Male & 1508 & 34.9 & 401 & 40.6 & \\
\hline \multicolumn{6}{|l|}{ Education } \\
\hline $\begin{array}{l}\text { Less than High } \\
\text { School }\end{array}$ & 709 & 16.4 & 264 & 26.7 & \multirow{7}{*}{.0001} \\
\hline $\begin{array}{l}\text { High School } \\
\text { /GED/ Some }\end{array}$ & 1804 & 41.8 & 424 & 43.0 & \\
\hline College & & & & & \\
\hline College & & & & & \\
\hline /Associate & 1788 & 41.4 & 293 & 29.7 & \\
\hline $\begin{array}{l}\text { Degree or } \\
\text { Higher }\end{array}$ & & & & & \\
\hline No Response & 14 & 0.4 & 6 & 0.6 & \\
\hline \multicolumn{6}{|l|}{ Income } \\
\hline Low & 533 & 12.4 & 169 & 17.1 & \multirow{5}{*}{.0001} \\
\hline Medium & 906 & 21.0 & 225 & 22.8 & \\
\hline High & 1112 & 25.8 & 206 & 20.9 & \\
\hline Affluent & 1120 & 25.9 & 201 & 20.4 & \\
\hline No Response & 644 & 14.9 & 186 & 18.8 & \\
\hline
\end{tabular}

A comparison of those participants' responses revealed that there was some difference in gender $(p=$ $0.0008)$, education $(p=0.0001)$, and income $(p=0.0001)$, but not enough to impact the validity of the survey, especially because of the large number of participants who completed the survey (81.4\%) compared to the small numbers $(18.6 \%)$ who did not respond. Age of the participants at Home Induction did not reveal any significant differences relevant to the study and is not 
included in the table. Because the response rate was $81.4 \%$, assessing whether there were differences between the types of individuals who participated in the CSI-SF ( $n$ $=4315)$ and those who did not $(\mathrm{n}=987)$ was not critical to the results of this study.

The mean, standard deviation, and median from total scores obtained on the scales and sub-scales of the CSISF are summarized in Table 2. Cronbach's Alpha coefficients were computed for each of the four sub-scales of the CSI-SF to estimate internal consistency reliability (Table 2). All dimensions were shown to have marginal to acceptable levels of reliability (alpha $=0.58-0.72$ ). Coefficients ranged from 0.58 to 0.72 for second tier subscales, which are Problem-Focused engagement, Problem-Focused Disengagement, Emotion-Focused Engagement, and Emotion-Focused Disengagement, and 0.59 and 0.70 for the first tier scales, Disengagement and Engagement respectively.

Table 2: Descriptive Statistics and Internal Consistency Reliability of Scales of CSI-SF

\begin{tabular}{|c|c|c|c|c|c|c|}
\hline \multirow{2}{*}{$\begin{array}{l}\text { Scale } \\
\text { PFE }\end{array}$} & \multirow{2}{*}{$\begin{array}{c}\text { Mean } \\
15.09102\end{array}$} & $S D$ & \multicolumn{2}{|c|}{ Median } & \multicolumn{2}{|r|}{$\begin{array}{l}\text { Internal } \\
\text { nsistency } \\
\text { eliability }\end{array}$} \\
\hline & & 2.63961 & \multicolumn{2}{|c|}{15.0000} & $4-20$ & 0.67 \\
\hline PFD & 11.57924 & 2.98357 & \multicolumn{2}{|c|}{12.0000} & $4-20$ & 0.60 \\
\hline EFE & 13.06231 & 2.90092 & \multicolumn{2}{|c|}{13.0000} & $4-20$ & 0.72 \\
\hline EFD & 11.41843 & 2.64538 & \multicolumn{2}{|c|}{11.0000} & $4-20$ & 0.58 \\
\hline $\mathrm{E}$ & 28.16370 & 4.56045 & \multicolumn{2}{|c|}{28.0000} & $8-40$ & 0.70 \\
\hline $\mathrm{D}$ & 22.97040 & 4.43641 & 123.0 & \multicolumn{2}{|c|}{$9-40$} & 0.59 \\
\hline \multicolumn{7}{|c|}{$\begin{array}{l}\text { PFE }=\text { Problem-Focused Engagement } \\
\text { PFD }=\text { Problem-Focused Disengagement } \\
E F E=\text { Emotion-Focused Engagement } \\
E F D=\text { Emotion-Focused Disengagement } \\
E=\text { Total Engagement } \text { D = Total Disengagement }\end{array}$} \\
\hline \multicolumn{7}{|c|}{$\begin{array}{l}\text { Table 3: Pearson Correlation of CSI-SF Scales and } \\
\text { Subscales }\end{array}$} \\
\hline \multirow[t]{2}{*}{ Scales } & \multicolumn{6}{|c|}{ Correlation coefficient } \\
\hline & PFE & $P F D$ & $E F E$ & $E F D$ & $E$ & $D$ \\
\hline PFE & 1.00 & $-0.09 \quad 0$ & $0.36^{*}$ & $-0.14^{*}$ & $0.80 *$ & $-0.15^{*}$ \\
\hline PFD & $-0.19^{*}$ & 1.00 & 0.05 & $0.19^{*}$ & -0.02 & $0.85^{*}$ \\
\hline EFE & $0.36^{*}$ & 0.05 & 1.00 & -0.07 & $0.84^{*}$ & 0.00 \\
\hline EFD & $-0.14^{*}$ & $0.19^{*}$ & -0.07 & 1.00 & $-0.13^{*}$ & $0.69 *$ \\
\hline $\mathrm{E}$ & $0.80^{*}$ & -0.02 & $0.84 *$ & -0.13 & 1.00 & -0.09 \\
\hline $\mathrm{D}$ & -0.15 & $0.85^{*}$ & 0.00 & $0.69 *$ & $-0.19 *$ & 1.00 \\
\hline
\end{tabular}

Table 4: The Survey Item Factor Loadings for the CSI-SF

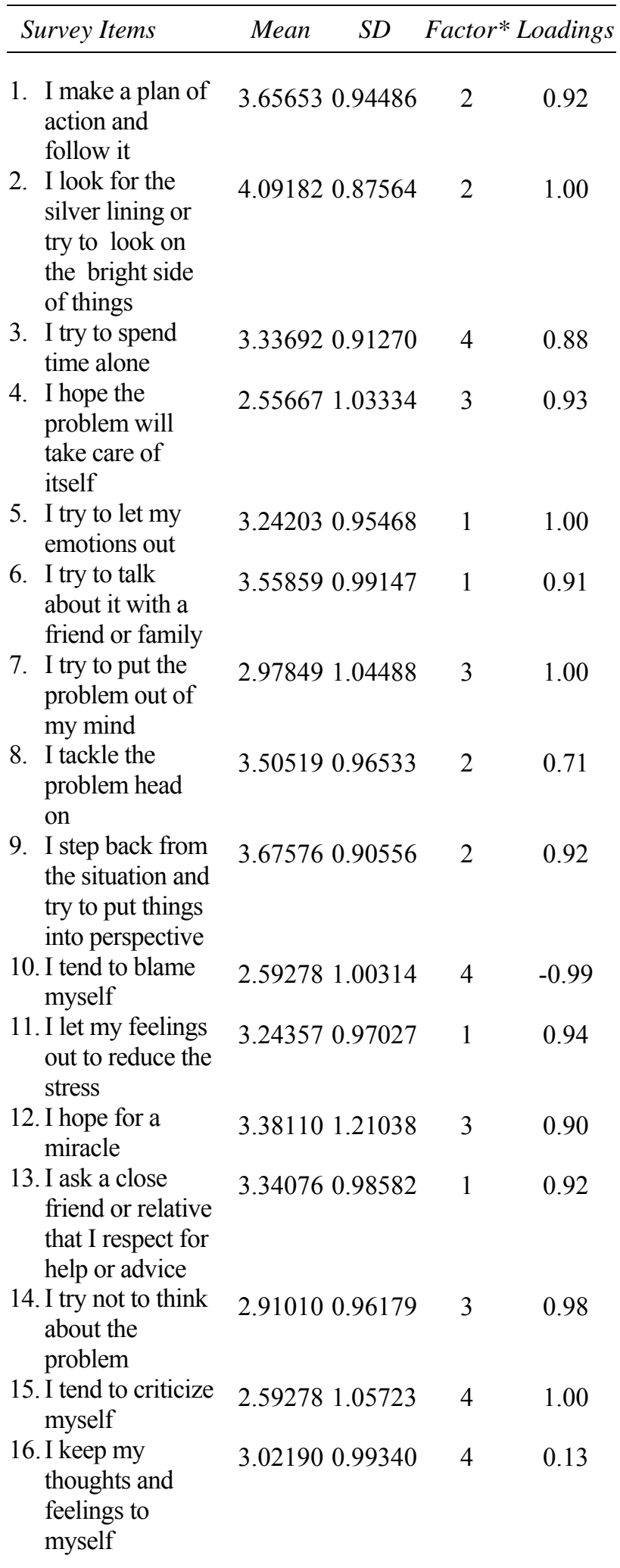

*1=Problem-Focused Engagement, 2=Problem-Focused Disengagement, 3=Emotion-Focused Engagement, 4= Emotion-Focused Disengagement.

Responding Scores $(1=$ never, $2=$ seldom, $3=$ sometimes, $4=$ often, $5=$ almost always) 
The analysis of the CFA produced a final confirmatory factor model with a good fit to the data. This was verified by the model fit indices. CFA was run based on a correlation matrix using maximum likelihood estimates, and the result indicated reasonable fit. The large chi-square value in Table 5 is due to the large sample size $(\mathrm{n}=4315)$. Although the chi-square test was significant, $\chi^{2}(78)=1455.9406, p<0.0001$, the model yielded acceptably high goodness of fit indices $(0.95$ and 0.93 ) for both the GFI and AGFI respectively. Bentler [39] and Joreskog \& Sorbom [40] warned against the sole use of the chi-square value in assessing the fit of the model because of the sensitivity of the chi-square to sample size.

Table 5: Results of a Confirmatory Factor Analysis of the Four Factor CSI-SF

\begin{tabular}{|c|c|c|c|}
\hline & Value & Chi-Square & Prob. \\
\hline $\begin{array}{l}\text { Goodness of Fit Index } \\
\text { (GFI) }\end{array}$ & 0.95 & & \\
\hline $\begin{array}{l}\text { GFI Adjusted for } \\
\text { Degrees of Freedom } \\
\text { (AGFI) }\end{array}$ & 0.93 & & \\
\hline $\begin{array}{l}\text { Root Mean Square } \\
\text { Residual (RMSR) }\end{array}$ & 0.05 & & \\
\hline $\begin{array}{l}\text { RMSEA Estimate } \\
\text { (RMSEA) }\end{array}$ & 0.06 & 1455.9406 & $<.0001$ \\
\hline $\begin{array}{l}\text { Parsimonious GFI } \\
\text { (Mulaik, 1989) (PGFI) }\end{array}$ & 0.76 & & \\
\hline $\begin{array}{l}\text { James, Mulaik \& Brett } \\
\text { (1982) Parsimonious } \\
\text { NFI (PNFI) }\end{array}$ & 0.66 & & \\
\hline
\end{tabular}

The Goodness of Fit Index (GFI), an indication of how well the observed variables in combination serve as measuring instruments for all latent variables jointly, was remarkably high (0.95). Because the GFI is considered a generalized indicator of reliability [41], the high coefficient score indicates that the measurement model is excellent. Results of CFA for the short form of the CSI reveal a sound model fit with Root Mean Square Residual (RMSR) of 0.05 and Root Mean Square Error of Approach (RMSEA) of 0.06. $\quad(<0.08$ signifies sound model fit). Finally, PGFI (0.76) and PNFI (0.66) indicate good model parsimony. Overall, these indices provide very strong support for the postulated measurement model for the CSI-SF.

\section{Conclusion}

Before deciding to use the CSI-SF, three main issues had to be addressed. The first was the reliability of the instrument. Secondly, we had to establish the validity of the instrument. Validity was assessed by examining how each item grouped onto a particular theme. Thirdly, we had to ensure that the CSI-SF was used appropriately, and adequately measured the coping skills of the JHS AfricanAmerican cohort.

Factor analysis highlighted the factors from each scale that could be useful in accurately identifying the coping behaviors of the JHS cohort. There is evidence that the items in each subscale of the CSI-SF are measuring the same underlying construct. They have good reliability in effectively measuring each individual subscale. This evidence was strengthened by the descriptive statistics that revealed sufficient variability in scores to warrant its use as an adequate measure. The major limitation of this study is the fact that some of the Cronbach alpha reliabilities for the subscales were not as strong as others in establishing sound reliability in all of the constructs.

This large number of participants and the large number of responses examined substantially improved the chance of achieving confidence in the analyses. All of the fit indices satisfied the range requirements that many researchers deem indicative of adequate fit. The four indicators of overall coping and the two sub-scales had reliabilities that were adequate for acceptance of the CSISF as a valid measure of the coping strategies used by the JHS cohort. This instrument seems to adequately identify the dimensions of coping that were earlier projected through the study done by Tobin, Holroyd, Reynolds \& Wigul [20].

Support for the scales of Problem-Focused Coping and Emotion Focused Coping as proposed by Lazarus [7] and Tobin, Holroyd, Reynolds \& Wigul [20] is evident. The fit indices and the reliabilities provide evidence that the factors presented in the CSI-SF adequately describe the structure of coping in the JHS cohort. Analysis of gender, age, educational level, and income of the participants who responded to the CSI-SF and those who did not, failed to provide any evidence of unusual bias or response variation that would affect validation of the CSI-SF.

The decision to include the CSI-SF in the Jackson Heart Study was based on the assumption that the survey and the data generated would meet minimum psychometric requirements for measuring this AfricanAmerican population. In order to accurately assess coping strategies in this community, it is important that the methods used to construct and score the scales and the summary measures be appropriate for the group under investigation. A major goal of the establishment of the psychometric properties is an evaluation of the consistency of psychometric results [27]. During this process of psychometric analysis, poor performing items are discarded [43]. In this study, item \# 16 was discarded making the CSI-SF a 15-item survey. This study has established the usefulness of the four- factor 15-item CSI$S F$ as a measure of coping in African Americans and provides empirical support for utilizing this instrument in future efforts to understand the role of coping in 
moderating health outcomes. Future researchers can now build upon our work by further applying the CSI-SF to research with similar populations.

Acknowledgements: This research from the Jackson Heart Study is supported by NIH contracts N01-HC95170, N01-HC-95171, and N01-HC-95172 provided by the National Heart, Lung, and Blood Institute and the National Center for Minority Health and Health Disparities.

Reference

1. Thon, T.; Haase, N.; Rosamond, W.; Howard, V. Y.; Rumfeield, J.; Manolio, T.: Heart disease and stroke statistics. Circulation, 2006, 113, e85-e151.

2. Pearcy, J. N.; Keppel, K. G.: A summary measure of health disparity. Public Health Report, 2002, 117:278-280.

3. Association of Black Cardiologists. Update on cardiovascular disease in African American. Focus on obesity, metabolic syndrome and diabetes. Symposium Presented at ABC International Library and Research and Conference Center, July 25, Atlanta, Ga, 2006

4. Wyatt, S. B.; Williams, D. R.; Calvin, R.; Henderson, F. R.; Walker, R. R.; Winters, K.: Racism and cardiovascular disease. The American Journal of the Medical Science, 2003, 325, 6, 315-331.

5. Lidfeldt, J.; Samsui, G.; Agardh, G.: Obese women and the relation between cardiovascular risk profile and hormone therapy, glucose tolerance and psychosocial conditions. Diabetes Care, 2006, 29, 2477-2482.

6. Levine, J.; Warrenburg, S.; Kerns, R.; Schwartz, G. The role of denial in recovery from coronary heart disease. Psychosomatic Medicine, 1987, 49,109-117.

7. Lazarus, R. S.: Emotion and adaptation. London: Oxford University Press, 2007.

8. Folkman, S.; Muskowitz, S. Positive affect and the other side of coping. American Psychologist, 2000. 55:647-654.

9. Larsen, M. R.; Langer, A. W.: Defensive hostility and anger expression: Relationship to additional heart rate reactivity during active coping. Psychophysiology, 1997, 34,177-184.

10. Holahan, C. J.; Moos, R. H.; Holahan, C. K.; Brennan, P. I.: Social support, coping, and depressive symptoms in a late-middle-aged sample of patients reporting cardiac illness. Health Psycholog, 1995, 14,152-163.

11. Penley, J. A.; Tomaka, J.; Weibe, J. S.: The association of coping to physical and psychological health outcomes: A meta-analytic review. Journal of Behavioral Medicine, 2002, 25,551-603.

12. Goldberger, R. L.; Brenznitz, S.: Handbook of stress. New York: The Free Press, 1982.
13. Ebata, A. T.; Moos, R. H.: Personal, situational and contextual correlation of coping in adolescence. Journal of Research on Adolescence, 2007, 4:99.

14. American Cancer Society. Cancer rates \& figures for African-Americans 2003-2004. American Cancer Society: Atlanta, Ga, 2007.

15. Ghafoor, A.; Jernal, A.; Cokkinided, V.; Cardinez, V.; Murray, T.; Samuals, V.; Thun, M. J.: Cancer statistics for African-Americans. A Cancer Journal for Clinicians, 2007, 52, 326-341.

16. Joslyn, S.; West, M.: Racial differences in breast carcinoma survival. Cancer, 2000, 88,114-123.

17. Reynolds, P.; Hurley, S.; Torres, M.; Jackson, J.; Boyd, P.; Chen, V.: Use of coping strategies and breast cancer survival: Results from the Black/White Cancer Survival Study. American Journal of Epidemiology, 2000, 152, 940-949.

18. Lazarus, R. S.; Averill, J. R.; Opton, E. M. Jr.: The psychology of coping: Issues for research and assessment. In Basic Books.Coelho. G.V.Eed.). New York: NY, 1974, 249-315.

19. Ashing-Giwa, K.: Quality of life and psychosocial outcomes in longterm survivors of breast cancer: A focus on African-American women. Journal of Psychosocial Oncology, 2007, 17:47-62.

20. Tobin, D. L.; Holroyd, K. A.; Reynolds, R. V.; Wigul, J. K.: The hierarchical factor structure of the Coping Strategies Inventory. Cognitive Therapy and Research, 1989, 13, 343-361.

21. Suls, J.; Fletcher, B.: The relative efficacy of avoidant and non-avoidant coping strategies: A metaanalysis. Health Psychology, 1985, 4, 249-288.

22. Krohne, H. W.: Vigilance and cognitive avoidance as concepts in coping research. In Attention and Avoidance: Strategies in Coping and Aversivenes. Krohne, H. W. (Ed.) Seattle, WA: Hogrefe \& Huber, 1993, 19-50.

23. Laux, L.; Weber, H. Coping with emotions, and selfpresentation. Stuttgart: Kohlhammer, 1993.

24. Helmers, K. F.; Krantz, D. S.; Merz, C. N. B.; Klein, J. Gottdeiner, W. J. Rozanski, A.: Defensive hostility: Relationship to multiple markers of cardiac ischemia in patients with coronary disease. Health Psycholog, 2007, 14, 202-209.

25. Filipp, S. H.; Klauer, T.; Fleming, D.: Self-focused attention in the face of adversity and threat. In: In Attention and Avoidance. H. W. Krohne (Ed.). Seattle, WA: Hogrefe \& Huber, 1993, 267-275.

26. Moos, R. H.; Shaffer, J. A.: Coping resources and processes: Current concepts and measures. In Handbook of Stress. Goldberg, L.; Bernit, S. (eds.). New York: Free Press, 1993, 234-257.

27. Gandek, B.; Sinclair, S. J.; Kosinski, M.; Ware, J. E. Jr.: Psychometric evaluation of the SF-36 health survey in medicare managed care. Health Care Financing Review, 2004.

28. Fuqua, S. R.; Wyatt, S. B.; Andrew, M. H.; Sarpong, D. F.; Henderson, F. R.; Cunningham, M. F.; Taylor, H. A. Jr.: Recruiting African-American research 
participation in the Jackson Heart Study: Methods, response rates, and sample description. Ethnicity \& Disease, 2005, 15, 4, S6-18-S6-29.

29. Payne, T. J.; Wyatt, S. B.; Mosley, T. H.; Dubbert, P. M.; Guitierrez-Mohamed, M. L.; Calvin, R.: Sociocultural methods in the Jackson Heart Study: Conceptual and descriptive overview. Ethnicity and Disease, 2005, 15, 4.

30. Jackson Heart Study (JHS). JHS Manual of Operations, Manual 2, Cohort Procedures. Jackson, MS: Jackson Heart Study, 2000.

31. Floyd, F. J.; Widaman, K. F.: Factor analysis in the development and refinement of clinical assessment instruments. Psychological Assessments, 1995, 7, 289-299.

32. Armstrong, S.; Overton, T.: Estimating non-response bias in Mail Survey. Journal of Marketing Research, 1977, 14, 296-402.

33. Spicer, J.: Making sense of multivariate data analysis. Thousand Oaks, CA: Sage Publications, 2005.

34. Meehl, P. E.: Why summaries of research on psychological theories are often uninterruptible. Psychological Reports, 1996, 66,195-244.

35. Byrne, B. M. A primer of LISREL. New York: Springer-Verlag, 1989.
36. Keyes, C. L. M.; Simotkin, D.; Ruff, C. D.: The empirical encounter of two traditions. Journal of Personality and Psychology, 2002, 82, 6, 10071022.

37. Stevens, J.: Applied multivariate statistics for the social sciences (3rd ed.). Mahwah, N. J: Lawrence Erlbaum, 2001.

38. Cronbach, 1. J.; Meele, P. E.: Construct validity in psychological tests. Psychological Bulletin, 1955; 52:281-302.

39. Bentler, P. M.: Comparative fit indices in structural models. Psychological Bulleti, 1990, 107, 238-246.

40. Joreskog, K.; Sorbom, D.: LISREL 7: User's reference guide. Mooresville, IN: Scientific Software International, Inc, 1989.

41. Klem, L.: Structural equation modeling. In Reading and Understanding More Multivariate Statistics. Grimm, L. G. (ed.), 2000, 227-260.

42. Henderson, P. D.; Fugel, J.; Edwards, Q. T.: Coping strategies among African American women with breast cancer. Southern On-line Journal of Nursing Research, 2003, 4, 3,

43. Rozkoszkowski, M. J.; Davey, G.; Grable, J. E.: Insights from psychology and psychometrics on measuring risk tolerance. FPA Journal, 2005, 8. 